\title{
Case study research: Optical digitization, reverse engineering and rapid prototyping as a solution in pedal car development process
}

\author{
Pavel Stoklasek ${ }^{1, *}$, Tomas Vecera ${ }^{2}$ and Jiri Moravek ${ }^{3}$ \\ ${ }^{1}$ Tomas Bata University in Zlin, nam. T.G. Masaryka 5555, 76001 Zlin, Czech Republic \\ ${ }^{2}$ Czech Pedal Car, Sazovice 171, 76301 Myslocovice, Czech Republic \\ ${ }^{3}$ HM Model, Zdanska 906, 68501 Bucovice, Czech Republic
}

\begin{abstract}
The motivation of this work was to find an appropriate manufacturing method for pedal car accessories. This study describes the application of optical digitization, reverse engineering and rapid prototyping in manufacturing process of accessories for handmade pedal car, which imitates an unique historic Czech car, a Škoda 1000 MB, type 990 Roadster. Two well-known design elements, rear light and front indicator, were digitized by non-contact 3D scanner. The digitized 3D models were used as an inputs for reverse engineering. Their shapes were modified due to technological limits of vacuum forming, scaled and used to design of the 3D printed vacuum forming moulds. The final parts were made of transparent foil, trimmed around the perimeter and airbrushed from the inside. The described process served to verify the manufacturability of these accessories before commencing works on a mass-produced pedal cars intended for sale to customers.
\end{abstract}

\section{Introduction}

Reverse engineering and optical digitization are currently used in many sectors of industry and are an essential part of the designing of new products or optimizing of the production. Optical digitization of real objects allows quick and accurate creation of computer STL model that can be used as input for further processing in areas like mechanical engineering, quality control, forensic science, archaeology or prostheses and orthoses production [1-5].

Several types of scanners can be used for objects digitization - contact (coordinate measuring machine) or non-contact (magnetic, reflexive, trans-missive). The output data from scanners are mostly in form of cloud points that need to be further processed. This operation is called reverse engineering [6].

In the field of mechanical engineering, 3D optical scanners based on structured light projection are most commonly used to digitize real objects. The specially designed structures of projected patterns make it possible to digitize not only static but also dynamic scenes. Optical digitization is often used when 3D data, drawings or other documentation, from which a scanned part can be recreated, are missing. It can also be used in the case of digital preservation e.g. the digitization of stone or masonry structures, parts of historical buildings and other cultural heritages [7].

Another examples of using of the optical digitization is a digital reconstruction of a damaged parts of objects or some of its missing parts, weight or cost reduction [8], or improvement of functionality [9].

The main objective of reverse engineering $(\mathrm{RE})$ is to obtain a parametric model from scanned data which corresponds as much as possible to the original object. This model has a fully defined creation history and the same functionality and geometric accuracy as the original part [10-14].

Very often, RE is also used for designing in automotive or aircraft industry [15-17]. However, RE may be used advantageously in other sectors of industry as well - for example in the development of toys.

This case study deals with the development of rear lights and front indicators for a pedal car. The pedal car is a scaled replica of the real car intended for children. An example of pedal car is shown in Figure 1.

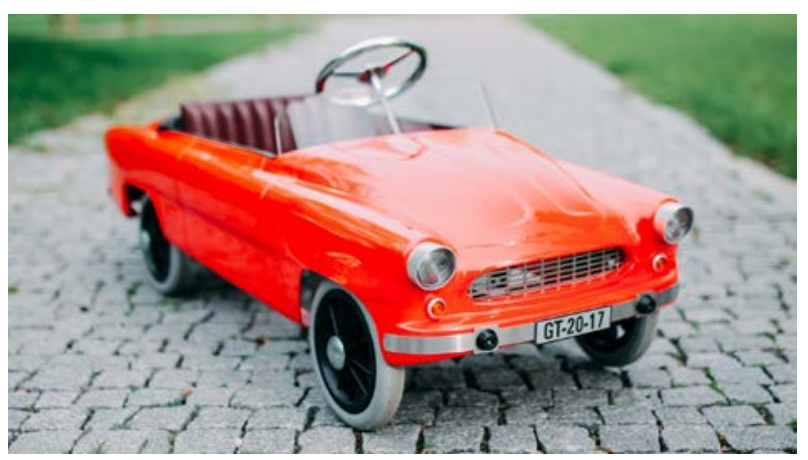

Fig. 1. Pedal car, inspired by Škoda Felicia (1959).

\section{Corresponding author: pstoklasek@utb.cz}


The pedal car consists of a metal frame with a pedal mechanism, leather seat, steering wheel and laminate bodywork. All external accessories such as lights, winkers, bumpers and other visual elements are fastened to the bodywork.

The original car used in this case study as an inspiration for a pedal car design - Škoda $1000 \mathrm{MB}$, type 990 roadster - is shown in Figure 2.

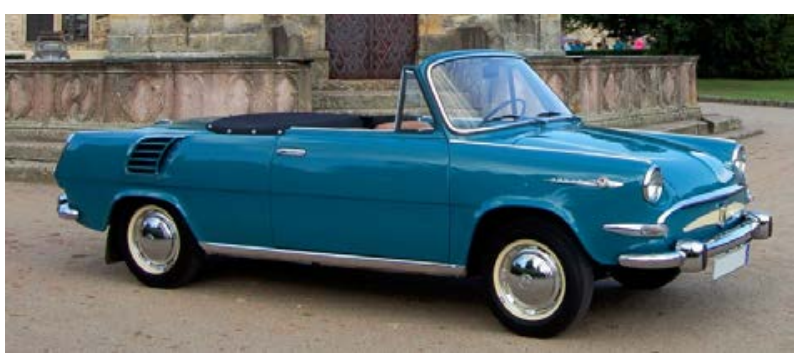

Fig. 2. Škoda $1000 \mathrm{MB}$, type 990 roadster.

\section{Experimental}

For the purpose of this work, slightly damaged parts rear light and front indicator of Škoda 1000 MB were used.

Non-contact 3D scanner ATOS II TripleScan 5M (GOM, Germany) with parameters presented in Table 1 was used for digitizing.

Table 1. Measurement parameters

\begin{tabular}{|l|c|}
\hline Scanning technology & $\begin{array}{c}\text { Blue light technology with } \\
\text { fringe patterns projection }\end{array}$ \\
\hline Resolution & $5 \mathrm{MPix}$ \\
\hline Measurement volume & $320 \times 240 \times 240 \mathrm{~mm}$ \\
\hline Reference points & circle, $\varnothing 1.5 \mathrm{~mm}$ \\
\hline No. of shutter times & 1 \\
\hline Shutter time & \multicolumn{1}{|c|}{$25 \mathrm{~ms}$} \\
\hline Scan detail option & High quality / Full resolution \\
\hline
\end{tabular}

\subsection{Optical digitization}

\subsubsection{Optical digitization of pedal car bodywork}

The dimensions of the bodywork master-model were approximately 1150 × $500 \times 250 \mathrm{~mm}$. More than 180 strategically placed reference points have been used for ensuring a proper 3D scanning of the whole surface. Due to a good visual properties of the matte paint no additional anti-reflective coating was required.

A model of pedal car bodywork was digitized to get a real-sized 3D computer model. The wooden model served as a master-model for producing a multi-part mould for bodywork laminating. The exact scale of the master-model reduction (compared to the original car) was not known because it was hand-carved according to historical photos and drawings. The master-model of the pedal car bodywork after surface finish (the filler application, grinding with the sandpaper and matte paint spraying) is shown in Figure 3.

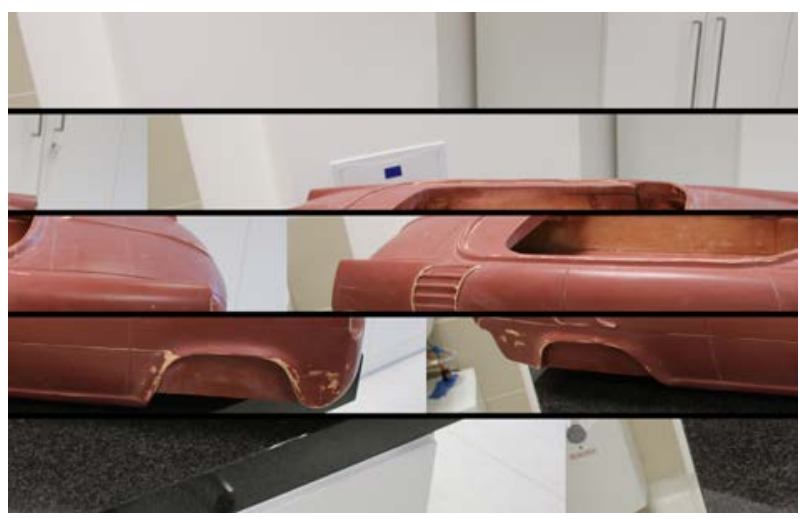

Fig. 3. Wooden model of the pedal car bodywork.

The digitized model of the bodywork consisted of 76 snapshots from different angles. The entire surface of the model has been edited in the program GOM Professional (GOM, Germany). Several important corrections have been made - mesh cleaning, minor irregularities eliminating, small holes filling and smoothing of the entire surface of the bodywork. The edited data was aligned and exported to STL (Standard Triangulation Language) format. The total scanning time of the bodywork was 50 minutes, the post-processing operations and alignment creation took 55 minutes. Figure 4 shows the final mesh of the bodywork after editing session.

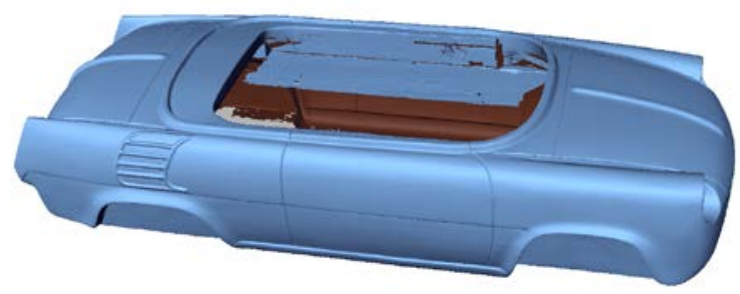

Fig. 4. Triangle mesh of the pedal car bodywork after postprocessing operations.

\subsubsection{Optical digitization of pedal car accessories}

The same accessory (including the same 3D scanner measurement parameters) was used to scan other bodywork parts. A front winker and a rear light were used for digitizing in this study. Both of these parts (shown in Figure 5) are inherently connected to the original design of Škoda $1000 \mathrm{MB}$ and for many people serve as its typical distinguishing features. Both parts are reversed symmetrically about a horizontal axis and can be used for both the left and right side of the pedal car. 


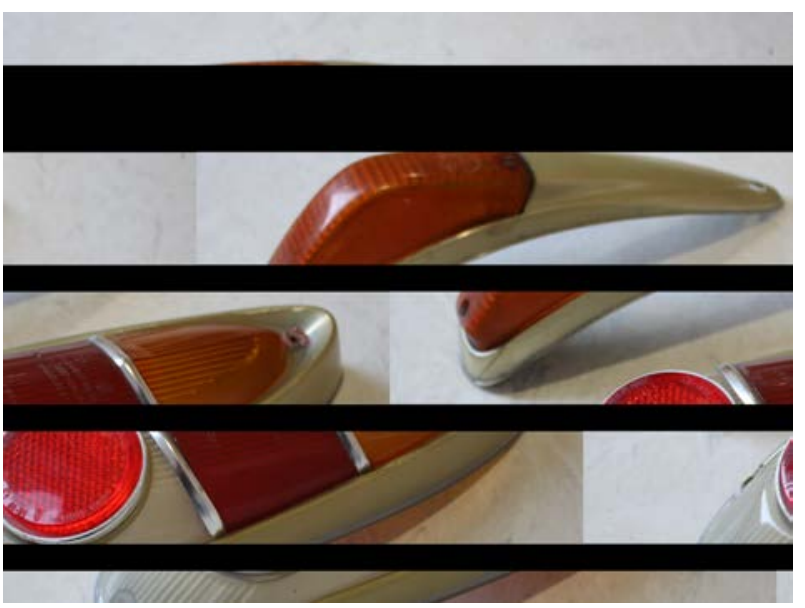

Fig. 5. Front indicator and the rear light of Škoda 1000 MB.

Around 30 reference points were placed on each scanned part. Due to higher reflectivity of used plastic materials, anti-reflective coating MR® 2000 Anti-Reflex L (MR Chemie, Germany) with chalk powder was used.

After the digitization, the same post-processing operations as in the previous case were made. Due to visual defects on the front indicator, the post-processing of this object required more time. The final result of the front indicator post-processing operations is shown in Figure 6 .
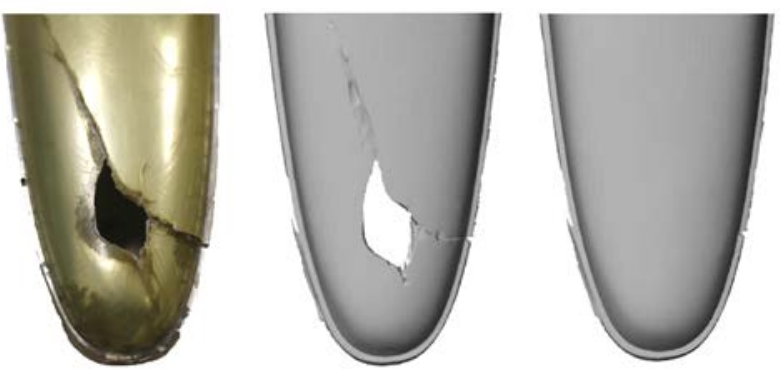

Fig. 6. Original part (left), raw 3D scan (middle) and postprocessed 3D scan (right).

All operations associated with optical digitization are summarised in Table 2. Figure 7 shows the final postprocessed meshes of the bodywork accessories.

Table 2. Summary of optical digitization

\begin{tabular}{|l||c|c|c|}
\hline Part & Bodywork & $\begin{array}{c}\text { Front } \\
\text { indicator }\end{array}$ & Rear light \\
\hline \hline $\begin{array}{l}\text { No. of reference } \\
\text { points used }\end{array}$ & 182 & 27 & 33 \\
\hline No. of snapshots & 76 & 13 & 15 \\
\hline Pre-processing & $35 \mathrm{~min}$ & $5 \mathrm{~min}$ & $6 \mathrm{~min}$ \\
\hline Scanning time & $50 \mathrm{~min}$ & $8 \mathrm{~min}$ & $10 \mathrm{~min}$ \\
\hline Post-processing & $55 \mathrm{~min}$ & $25 \mathrm{~min}$ & $8 \mathrm{~min}$ \\
\hline \hline Total time & $\mathbf{1 4 0} \mathbf{~} \mathbf{m i n}$ & $\mathbf{3 8} \mathbf{~} \mathbf{m i n}$ & $\mathbf{2 4} \mathbf{~} \mathbf{m i n}$ \\
\hline
\end{tabular}

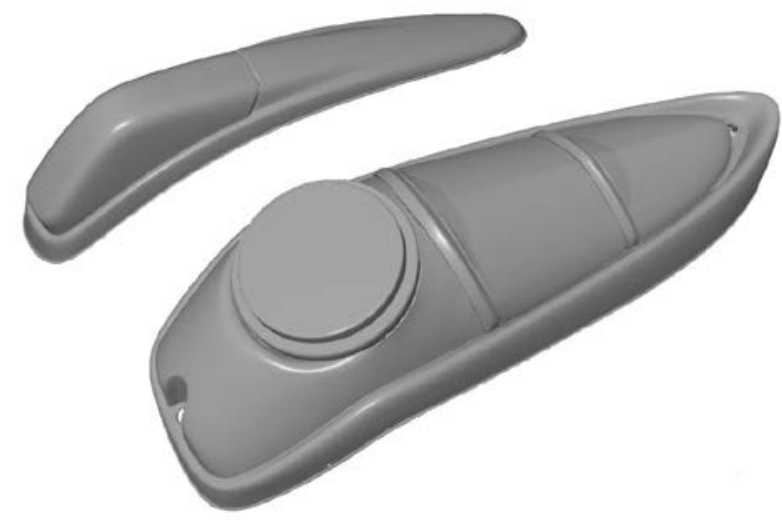

Fig. 7. Triangle meshes of front indicator and the rear light after post-processing operations.

\subsection{Reverse Engineering and vacuum moulds design}

Software Geomagic Design X (3D Systems, Inc., USA) was used for Reverse Engineering of both scanned parts. First, it was necessary to determine the exact scale of the bodywork reduction (compared to the original car). The measured value was used for correct scaling of the scanned accessories that were placed on the matching positions of the bodywork 3D scan.

Due to the manual carving of the bodywork mastermodel, significant deviations were found between the bodywork surface and the surfaces of the lights. These deviations were eliminated by the RE process. The adjustment of the non-matching mounting faces of rear light is shown on Figure 8.

For reasons of technological limitations of vacuum forming, the appropriate bevels have been added to the 3D model. The total time of RE of rear light was 3.5 hours, the $3 \mathrm{D}$ data of the front winker were created in 2.25 hours.
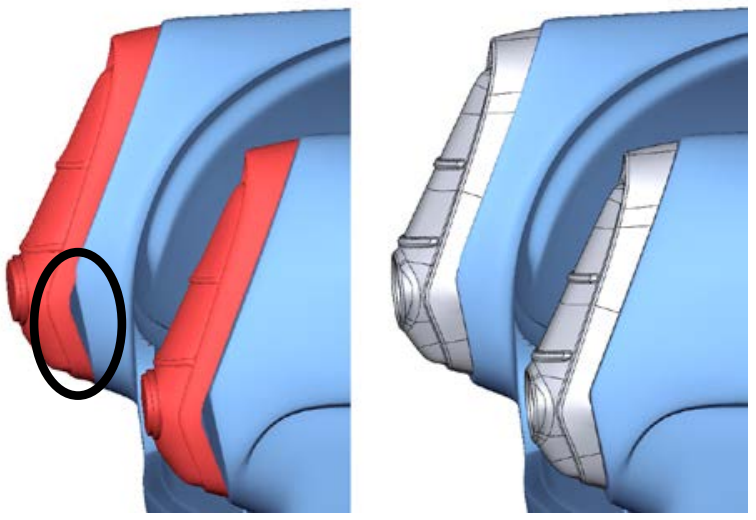

Fig. 8. Adjustment of non-matching mounting faces between the bodywork and the rear light.

The generated 3D data were used for the design of the vacuum forming moulds (mould of the rear light is shown in Figure 9). On the basis of the created solid models of moulds, the FDM (Fused Deposition Modelling) 3D printing process was realized. The material ABS M30 Black was used for production. The 
surfaces of both moulds were post-processed - sanding, grinding and acetone vaporizing were applied.

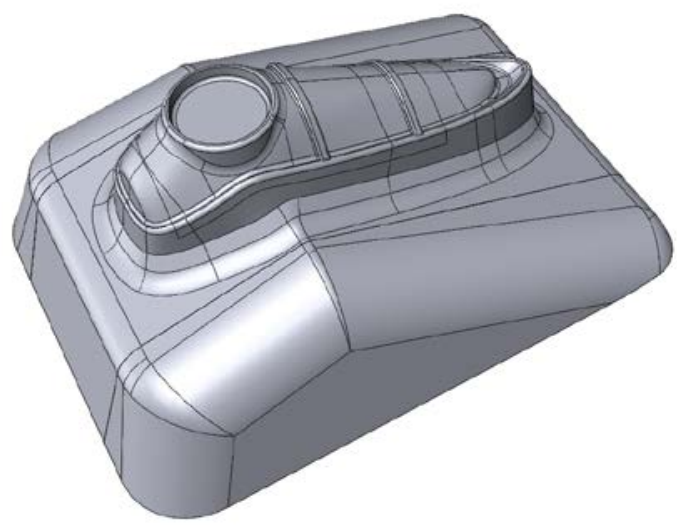

Fig. 9. 3D model of vacuum forming mould (rear light).

During the vacuum forming, the melted plastic was deformed to the desired shape (the male-mould shape was copied). Transparent, $1 \mathrm{~mm}$ thick PE foil was used for vacuum forming. The result of this operation is shown in Figure 10. After vacuum forming, both shaped foils were trimmed into a defined shapes and airbrushed from the inside. The final prototype of rear light after these operations is shown in Figure 11. The rear side of both parts (the contact surface with the pedal car bodywork) was sealed and supplemented with mounting elements.

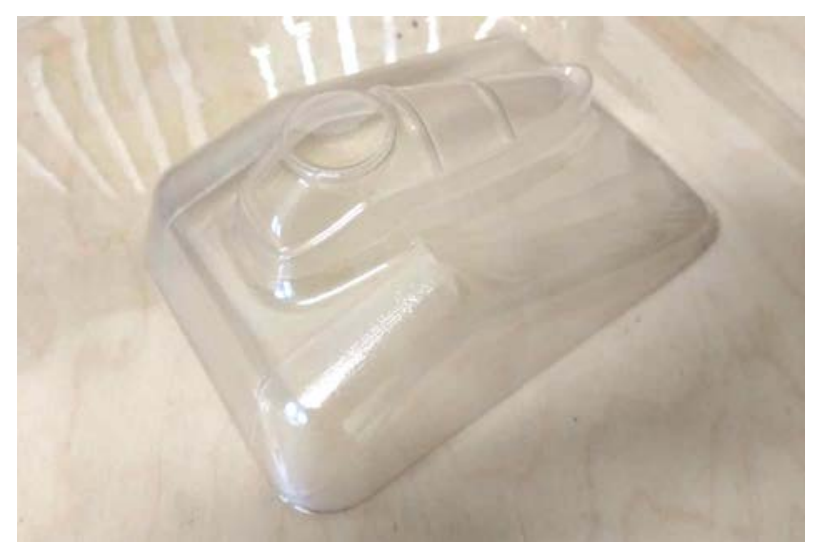

Fig. 10. The result of the vacuum forming (the rear light).

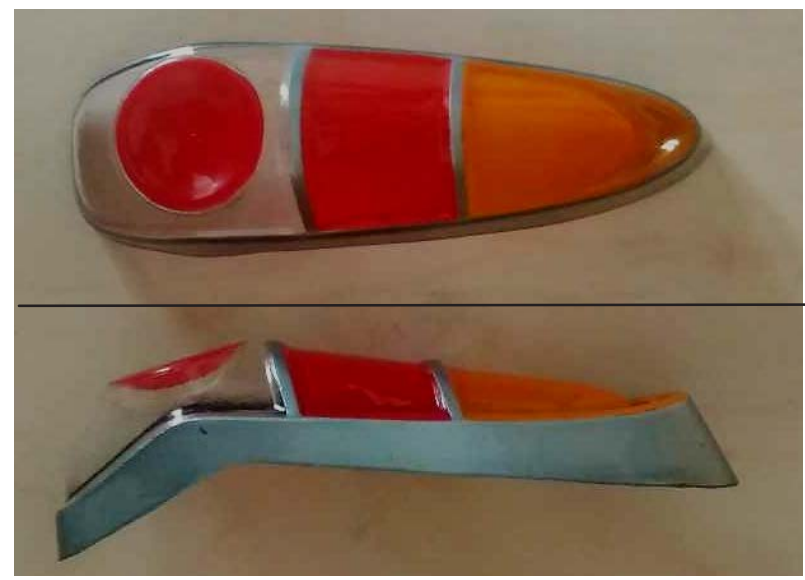

Fig. 11. The final prototype of rear light cover.

\section{Results}

The aim of this case study was to find and test the appropriate technologies for a pedal car design accessories production. The optical digitization was used to obtain the shapes and reverse engineering served to design vacuum forming moulds. These moulds were subsequently 3D printed by using FDM technology and practically tested. More than 25 prototype parts were made from each mould without any signs of mould surface damage. Using 3D scanning, reverse engineering and $3 \mathrm{D}$ printing, the development process of pedal car accessories accelerated considerably.

The described process confirmed an appropriate choice of final production technology of rear light and front indicator covers - vacuum forming, and verified the manufacturability of small accessories before commencing works on a mass-produced pedal cars intended for sale to customers.

The assembled prototype of the pedal car Škoda 1000 MB, type 990 roadster compared to original design is shown in Figure 12 and Figure 13.

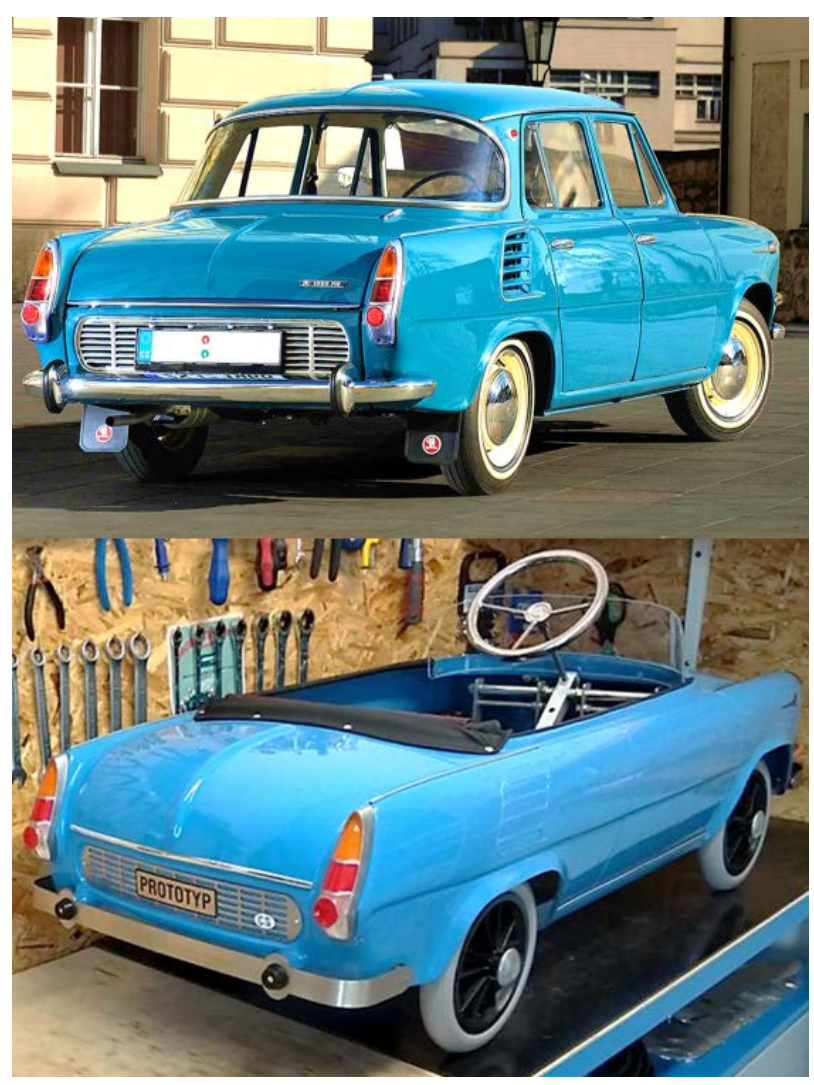

Fig. 12. Original design (upper part) compared to pedal car prototype (lower part). 


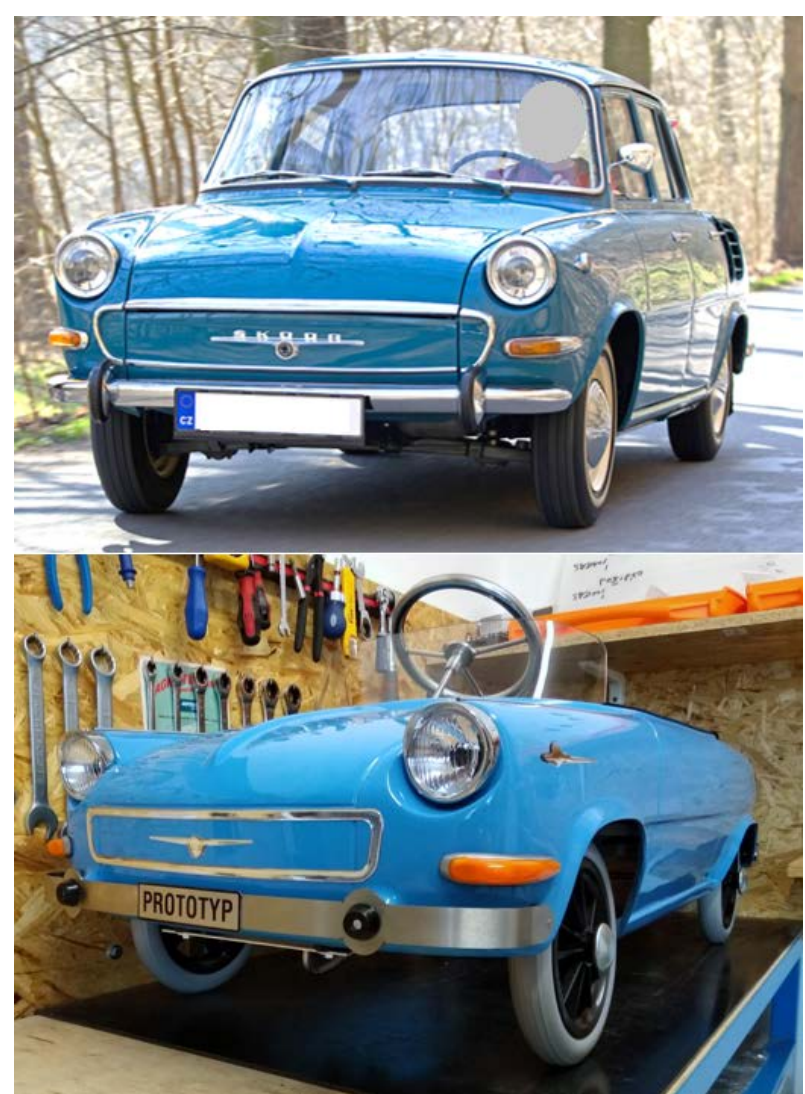

Fig. 13. Original design (upper part) compared to pedal car prototype (lower part).

This paper is supported by the internal grant of TBU in Zlin No. IGA/FT/2018/012 funded from the resources of specific university research, by the Czech Ministry of Industry and Trade in Program "Aplikace" No. CZ 01.1.02/0.0/0.0/16_084/0009949 and by the Ministry of Education, Youth and Sports of the Czech Republic within the National Sustainability Programme project No. LO1303 (MSMT-7778/2014) and also by the European Regional Development Fund under the project CEBIA-Tech No. CZ.1.05/2.1.00/03.0089.

The work described in this paper was completed in cooperation with the producer of pedal cars, Czech Pedal Car in Sazovice and Tomas Bata University in Zlin.

\section{References}

1. D. Koutny, D. Palousek, T. Koutecky, A. Zatocilova, J. Rosicky and M. Janda, World Acad. Sci. Eng. Technol., 6, 1468 - 1475, (2012).

2. I. Gibson, L.K. Cheung, S.P. Chow, W.L. Cheung, S.L. Beh, M. Savalani, S.H. Lee, Rapid Prototyping J., 12, 53-58 (2006).

3. G. Baronio, S. Harran, A. Signoroni, Applied bionics and biomechanics, Appl. Bionics Biomech, 2016, 1-7, (2016).

4. L. Cipriani, F. Fantini, (2017). The International Archives of Photogrammetry, Remote Sensing and Spatial Information Sciences, 42, 195-202 (2017).
5. D. Palousek, J. Rosicky, D. Koutny, Prosthet. Orthot. Int,. 38, 171 - 175, (2013).

6. B. Gapinski, M. Wieczorowski, L. MarciniakPodsadna, B. Dybala and G. Ziolkowski, Procedia Engineer., 69, 255-262, (2014).

7. J. Xu, L. Ding, P.E.D. Love, Automat. constr., 76, 85-96, (2017).

8. B. Vijaya Ramnath, C. Elanchezhian, J. Jeykrishnan, R. Ragavendar, P.K. Rakesh, J. Sujay Dhamodar, A. Danasekar, Mater. Today-Proc., 5, 994-999, (2018).

9. L. Chen, G. C. I. Lin, Robot. Cim-Int. Manuf., 16, 161-167, (2000).

10. M. Paulic, T. Irgolic, J. Balic, F. Cus, A. Cupar, T. Brajlih, I. Drstvensek, Procedia Engineer., 69, 795803, (2014).

11. F. Buonamici, M. Carfagni, R. Furferi, L. Governi, A. Lapini, Y. Volpe, J. Comp-D. Eng., 5, 145-159, (2018).

12. P. Benko;, G. Kós, T. Várady, L. Andor, R. Martin, Comput. Aided Geom. D., 19, 173-205, (2002).

13. N. Anwer, L. Mathieu, CIRP Annals, 65, 165-168, (2016).

14. F. Bosché, Adv. Eng. Inform., 24, 107-118, (2010).

15. K. Sokół, D. Cekus, Procedia Engineer., 177, 210217, (2017).

16. G. Sansoni, F. Docchio, Robot. Cim-Int. Manuf., 20, 359-367, (2004).

17. M. Burston, R.Sabatini, A. Gardi, R. Clothier, Appl. Mech. Mater., 629, 164-169, (2014). 